\title{
Hypertensive Patients' Knowledge of Risk Factors and Warning Signs of Stroke at Felege Hiwot Referral Hospital, Northwest Ethiopia: A Cross-Sectional Study
}

\author{
Addisu Taye Abate $\mathbb{D}$, Netsanet Bayu $\mathbb{D}$, and Tesfamichael G. Mariam \\ University of Gondar, College of Medicine and Health Sciences, School of Nursing, Department of Medical Nursing, Gondar, Ethiopia \\ Correspondence should be addressed to Addisu Taye Abate; addisutaye60@gmail.com
}

Received 9 December 2018; Revised 19 March 2019; Accepted 8 June 2019; Published 23 June 2019

Academic Editor: Changiz Geula

Copyright (C) 2019 Addisu Taye Abate et al. This is an open access article distributed under the Creative Commons Attribution License, which permits unrestricted use, distribution, and reproduction in any medium, provided the original work is properly cited.

\begin{abstract}
Background. Stroke is a neurological condition which is a major cause of death and disability in many low- and middle-income countries. However, several modifiable risk factors are becoming significant. Hypertension is the most common stroke risk factor globally as well as in our country, Ethiopia. Objective. The aim of this study was to assess hypertensive patients' knowledge of risk factors and warning signs of stroke at Felege Hiwot Referral Hospital, Northwest Ethiopia, 2018. Method. An institutional based cross-sectional study design was conducted in May 01-30/2018. A total of 278 hypertensive patients were enrolled and systemic random sampling technique was employed to select the study participants. Data was collected through an interviewer-administered questionnaire. The collected data was entered into Epi info 7 and exported to SPSS version 22 for analysis. Binary and multivariable logistic regressions were used and $P$ value $\leq 0.05$ was considered as statistically significant. Result. Out of the total 284 selected hypertensive patients, 278 of them responded completely with a response rate of $97.9 \%$. Of these, more than three fourths, 214 (77\%) and 201 (72.3\%), of them did not identify any risk factors and warning signs of stroke, respectively, with an overall proportion of only $18.3 \%$ of them having good knowledge towards stroke. Risk factor of stroke most commonly known to the respondents was physical inactivity (21.58\%), whereas hypertension was the least described risk factor (3.6\%). Regarding stroke warning signs, sudden weakness on one side of the body $(35.97 \%)$ was the most commonly known warning sign of stroke to the respondents. Being able to read and write, being young, urban residence, and having sufficient monthly income were significantly associated with the overall knowledge of hypertensive patients towards stroke. These findings suggest the need for emphasizing on stroke education regarding its risk factors and warning signs through public or social media and health education targeting to low-income high risk subjects.
\end{abstract}

\section{Introduction}

Stroke or cerebrovascular accident, which considerably affects the individuals' entire quality of life, is the third leading cause of death worldwide, with an incidence of approximately 15 million cases per year [1], and its fatality is more in Sub-Saharan Africa countries, which showed that $85 \%$ of global death from stroke occurred in these countries [2, 3]. In Ethiopia, lines of evidence showed that stroke is the commonest cause of admissions (45\%) from other neurologic diseases [4] and it accounted for 28,320 (4.71\%) of total deaths in Ethiopia [5].
Hypertension is described as one of the most common causes of stroke; and the incidence of stroke among hypertensive patients is increasing in developing countries [6]. Unlike that of developed countries, ischemic stroke, which is mostly associated with poor control of hypertension, is the commonest type of stroke in Africa [7-9].

Identification of the major lifestyle risk factors of stroke and its warning signs has a direct implication for the prevention of stroke with the possible therapeutic measures in high risk group such as hypertensive patients [10]. In addition, poor knowledge leads to low compliance in making use of preventive programmes [11, 12]. Despite this, most 
of Ethiopian hypertensive patients primarily presented to traditional healers who would not provide correct knowledge about stroke; and there is also lack of baseline data regarding knowledge of hypertensive patients towards stroke. Thus, patients are more likely to develop stroke and its complication $[13,14]$. As a result, hypertensive related stroke death in Ethiopia has reached 28,320 (4.71\%) of total deaths [14], which tells us how big the problem is and that it needs immediate attention. In this regard the results of this study would provide information on the knowledge of hypertensive patients towards stroke. Therefore, the aim of this study is to assess knowledge of hypertensive patients towards stroke risk factors and warning signs at Felege Hiwot Referral Hospital in Bahir Dar town, Northwest Ethiopia, 2018.

\section{Methods}

2.1. Study Design, Setting, and Period. An institution based cross-sectional study was conducted on 278 patients attending follow-up on hypertension in May 01-30/2018 at Felege Hiwot Referral Hospital, which is found in Amhara national regional state, Ethiopia.

2.2. Sample Size Determination and Procedure. The source population were all hypertensive patients who were on follow-up at Felege Hiwot Referral Hospital and those individuals who were under follow-up during data collection time were considered as a study population. All hypertensive patients who were on follow-up visit for at least 6 months during the study period and aged above or equal to 18 years old were included, whereas patients who already developed stroke before data collection period and those who were critically ill, with severe mental illness, or who were unable to provide the required information by themselves were excluded. To determine the required sample size of 284 participants, single population proportion formula was used with the assumption of $95 \%$ confidence interval, $5 \%$ margin of error, and $50 \%$ proportion of hypertensive patients who have good knowledge towards stroke, as there was no similar study in the area. Systematic random sampling technique was utilized; sampling interval " $\mathrm{K}$ " value was calculated as $\mathrm{K}=\mathrm{N} / \mathrm{nf}$, where $\mathrm{N}=$ the expected number of hypertensive patients per month $=814$ and $\mathrm{nf}=$ final sample size $=284$ which gives a sampling interval of three. Thus, using patients' record order which was listed in follow-up appointment as a sampling frame, participants were selected in every 3 number intervals until reaching the total sample size and the first participant was selected by lottery method.

2.3. Data Collection Method and Survey Instrument. Data collection was performed by four BSc nurses through an interviewer-administered questionnaire. The data collectors were properly trained on the instrument and ways of approaching the patients and how to obtain permission for an interview prior to the data collection process for three days. A standardized questionnaire already used in previous studies to assess knowledge of stroke risk factors and warning signs was adapted and applied for the study $[13,14]$. It comprises the sociodemographic variables, stroke risk factors, and stroke warning signs. The Stroke Recognition Questionnaire (SRQ) was used to determine whether hypertensive patients could identify stroke risk factors and symptoms. It uses a list of 10 stroke symptoms, 10-non-stroke related symptoms, 10 risk factors, and 10 non-stroke risk factors of stroke. Study subjects indicate by marking "yes" or "no" whether items on the list are stroke symptoms or risk factors. Then study participants' knowledge of stroke symptoms and warning signs was categorized based on the numbers of stroke symptoms and warning signs, respectively. In this regard, individuals with good knowledge of stroke symptoms could identify 5-10 stroke symptoms. Similarly, individuals who identified 5-10 stroke warning signs were categorized as having good knowledge towards stroke warning signs $[15,16]$. To determine the overall knowledge score, closed-ended questions were used. In the closed-ended questionnaire, the maximum total score was 18 points; each question accounts 1 point for correct and 0 for incorrect answers; and the overall knowledge was assessed from the total score that was scored by the patients. After all, participants with a total knowledge score of $50 \%$ and above were considered as having good knowledge [15]. The analyses in this article focused on the questions on general stroke knowledge. Initially, the questionnaire was translated from English to the official/local language of the region (Amharic); then it was retranslated to English language to ensure consistency. To test the fitness of the questionnaire for the study setting, the data collection tool was pretested on 28 adult hypertensive patients who were not included in the final analysis.

\subsection{Operational Definition}

2.4.1. Body Mass Index (BMI). It is the ratio of weight in kilogram over the height in meter square; and participants with BMI >30 kilogram per meter square were considered as obese.

2.4.2. Hypertension. A diagnosis of high blood pressure: a doctor or health worker had told the participant that they had elevated blood pressure. It is defined as systolic blood pressure greater than or equal to $140 \mathrm{mmHg}$ and/or diastolic blood pressure greater than or equal to $90 \mathrm{mmHg}$ and/or receiving treatment for high blood pressure.

2.4.3. Physical Inactivity. It refers to participants who did not get 30-60 minutes of aerobic exercise three to four times per week.

2.4.4. Income. Those study participants with $\geq 5000$ Ethiopian birr/month were classified as having sufficient income.

2.4.5. Smoker. It refers to those participants who smoke any tobacco products (such as cigarettes, cigars, or rolled tobacco). 
2.4.6. Alcohol Drinker. It refers to those participants who consume a drink containing alcohol [17].

2.5. Statistical Analysis. All the data was checked visually, coded and entered into Epi Info version 7, and exported to Statistical Package for Social Sciences (SPSS) version 21 for analysis. Frequencies, percentages, and summary statistics like mean and standard deviation were examined to describe the data. Binary logistic regression was run to see the crude significant relations of each independent variable with the general knowledge score of hypertensive patients towards stroke. Then variables with $P$ value $\leq 0.2$ in bivariable logistic regression were again entered into multivariable logistic regressions. Finally, significant factors were identified based on adjusted odds ratio (AOR) included in 95\% confidence level at $P$ value $\leq 0.05$.

2.6. Ethical Considerations. Ethical clearance was obtained from the Ethical Review Committee (ERC) of the School of Nursing, University of Gondar. An official letter of permission was obtained from Felege Hiwot Referral Hospital administration as a getting way. After explaining the purpose of the study, verbal informed consent was obtained from each of the study participants. Personal identifiers were not included in the written questionnaires to ensure participants' confidentiality.

\section{Results}

3.1. Sociodemographic Characteristics of Study Participants. Out of the total 284 selected hypertensive patients, 278 of them responded completely with a response rate of $97.9 \%$. As it is illustrated in Table 1, almost half, 145 (52.2\%), of them were female and majority of the participants, 211 (75.9\%), were aged greater than 45 with the mean age of 54.4 SD that ranged from 19 to 88 . Regarding their educational status, about $154(55.4 \%)$ of them were unable to read and write (Table 1).

3.2. General Knowledge of Hypertensive Patients about Stroke. Only $60(21.6 \%)$ of hypertensive patients correctly define stroke as a condition that results from disruption of blood supply to the brain; 24 (8.6\%) of the participants think stroke is the same as heart attack and a small proportion of patients, $44(15.8 \%)$, correctly identified that stroke is a disease of the blood vessels in the brain. Based on the knowledge assessment tool, the minimum and maximum scores were 0 and 16 out of 18 with the mean score of 2.7 and only 51 (18.3\%) of the participants had good knowledge towards stroke.

3.3. Knowledge of Risk Factors of Stroke among Hypertensive Patients. From the total participants, most of them, 214 (77\%), did not identify any risk factors of stroke; 39 (14\%) identified 5 risk factors; 10 (3.6\%) identified 4 risk factors; and only $5(1.8 \%)$ identified 3 risk factors of stroke. The stroke risk factors most commonly known to the respondents were physical inactivity (21.6\%), being obese $(20.1 \%)$, and drinking alcohol (18.7\%). In contrast with this, hypertension was the least described risk factor, in which only 10 (3.6\%) of participants reported hypertension as a risk factor of stroke (Figure 1).

3.4. Knowledge of Warning Signs of Stroke among Hypertensive Patients. Regarding knowledge component of major warning signs of stroke, about $217(77.3 \%)$ of participants did not identify any warning signs of stroke. Whereas 40 (14.4\%) of them identified 5 and more warning signs, 15 (5.4\%) identified 4 warning signs and $2(0.7 \%)$ identified 3 warning signs. Sudden weakness or paralysis on one side of the body (35.9\%) and unusual severe headache (16.2\%) were the most commonly known signs and symptoms of stroke to the respondents.

3.5. Factors Associated with Knowledge of Hypertensive Patients towards Stroke. In the present study, hypertensive patients able to read and write were more knowledgeable $(\mathrm{AOR}=7.128$, CI 95\% 2.298-22.108) than those who were unable to read and write. Regarding age, young respondents (age less than 45) were more likely to have good knowledge (AOR=2.56, CI 95\% 1.115-6.015) than respondents who aged 45 and above. Similarly, urban residents were more knowledgeable ( $\mathrm{AOR}=3.2$, CI 95\% 1.042-9.874) compared to the rural residents; and study participants with sufficient monthly income were also more likely to have good knowledge $(\mathrm{AOR}=2.756$, CI 95\% 1.225-6.200) than participants with insufficient monthly income (Table 2).

\section{Discussion}

This study found that most of hypertensive patients have extremely limited knowledge of stroke risk factors, are not familiar with its warning signs, and are not aware that stroke is a disease of the blood vessels in the brain. Surprisingly the respondents' knowledge regarding stroke risk factors was almost similar with that of the warning signs of stroke, in which more than three fourths (77\% and $77.3 \%)$ of respondents did not identify any risk factors and warning signs of stroke, respectively. In general, only $18.3 \%$ of them had good knowledge towards stroke. This finding is contradicted with other studies in which at least half of the respondents knew one or more of the known risk factors of stroke $[13,16-18]$. Likewise, in contrast with the good knowledge of stroke reported in previous studies among patients in Saudi population [19-21], only few respondents in this study (15.8\%) knew stroke as a disease of the blood vessels in the brain. The possible reason for this difference might be due to the fact that half of participants in the current study were from rural communities, where education, income level, health facilities, and opportunity for education are generally expected to be lower; and these subjects are less likely to have exposure for new information including different social media.

In the current study, hypertension was the least described risk factor (3.6\%). However, it has been reported as an important risk factor [22], and it is extremely lower than earlier studies which have reported higher proportions in 
TABLE 1: Sociodemographic and clinical characteristics of hypertensive patients at Felege Hiwot Referral Hospital in Bahir Dar Town, Ethiopia, 2018.

\begin{tabular}{|c|c|c|}
\hline Variables & Frequency & Percent (\%) \\
\hline \multicolumn{3}{|l|}{ Age category } \\
\hline$<45$ & 67 & $24.1 \%$ \\
\hline$\geq 45$ & 211 & $75.9 \%$ \\
\hline \multicolumn{3}{|l|}{ Sex } \\
\hline Female & 145 & $52.2 \%$ \\
\hline Male & 133 & $47.8 \%$ \\
\hline \multicolumn{3}{|l|}{ Residence } \\
\hline Rural & 137 & $49.3 \%$ \\
\hline Urban & 141 & $50.7 \%$ \\
\hline \multicolumn{3}{|l|}{ Religion } \\
\hline Orthodox & 220 & $79.1 \%$ \\
\hline Muslim & 38 & $13.7 \%$ \\
\hline Protestant & 17 & $6.1 \%$ \\
\hline Adventist & 2 & $.7 \%$ \\
\hline Catholic & 1 & $.4 \%$ \\
\hline \multicolumn{3}{|l|}{ Marital status } \\
\hline Single & 16 & $5.8 \%$ \\
\hline Married & 200 & $71.9 \%$ \\
\hline Divorced & 22 & $7.9 \%$ \\
\hline Widowed & 40 & $14.4 \%$ \\
\hline \multicolumn{3}{|l|}{ Monthly income } \\
\hline Sufficient & 103 & $37.0 \%$ \\
\hline Insufficient & 175 & $63.0 \%$ \\
\hline \multicolumn{3}{|l|}{ Level of education } \\
\hline Unable to read & 154 & $55.4 \%$ \\
\hline Educated & 124 & $45.6 \%$ \\
\hline \multicolumn{3}{|l|}{ Occupation } \\
\hline Government worker & 62 & $23.3 \%$ \\
\hline Merchant & 41 & $14.7 \%$ \\
\hline Housewife & 34 & $12.2 \%$ \\
\hline Student & 13 & $4.7 \%$ \\
\hline Labour worker & 17 & $6.1 \%$ \\
\hline Farmer & 82 & $29.5 \%$ \\
\hline Others & 29 & $10.4 \%$ \\
\hline \multicolumn{3}{|l|}{ BMI } \\
\hline Normal & 253 & $91.0 \%$ \\
\hline Overweight & 22 & $7.9 \%$ \\
\hline Obese & 3 & $1.1 \%$ \\
\hline \multicolumn{3}{|l|}{ Smoking } \\
\hline Yes & 8 & $2.9 \%$ \\
\hline No & 270 & $97.1 \%$ \\
\hline \multicolumn{3}{|l|}{ Alcoholism } \\
\hline Yes & 22 & $7.9 \%$ \\
\hline No & 256 & $92.1 \%$ \\
\hline \multicolumn{3}{|l|}{ Chat chewing } \\
\hline Yes & 1 & $0.4 \%$ \\
\hline No & 277 & $99.6 \%$ \\
\hline
\end{tabular}




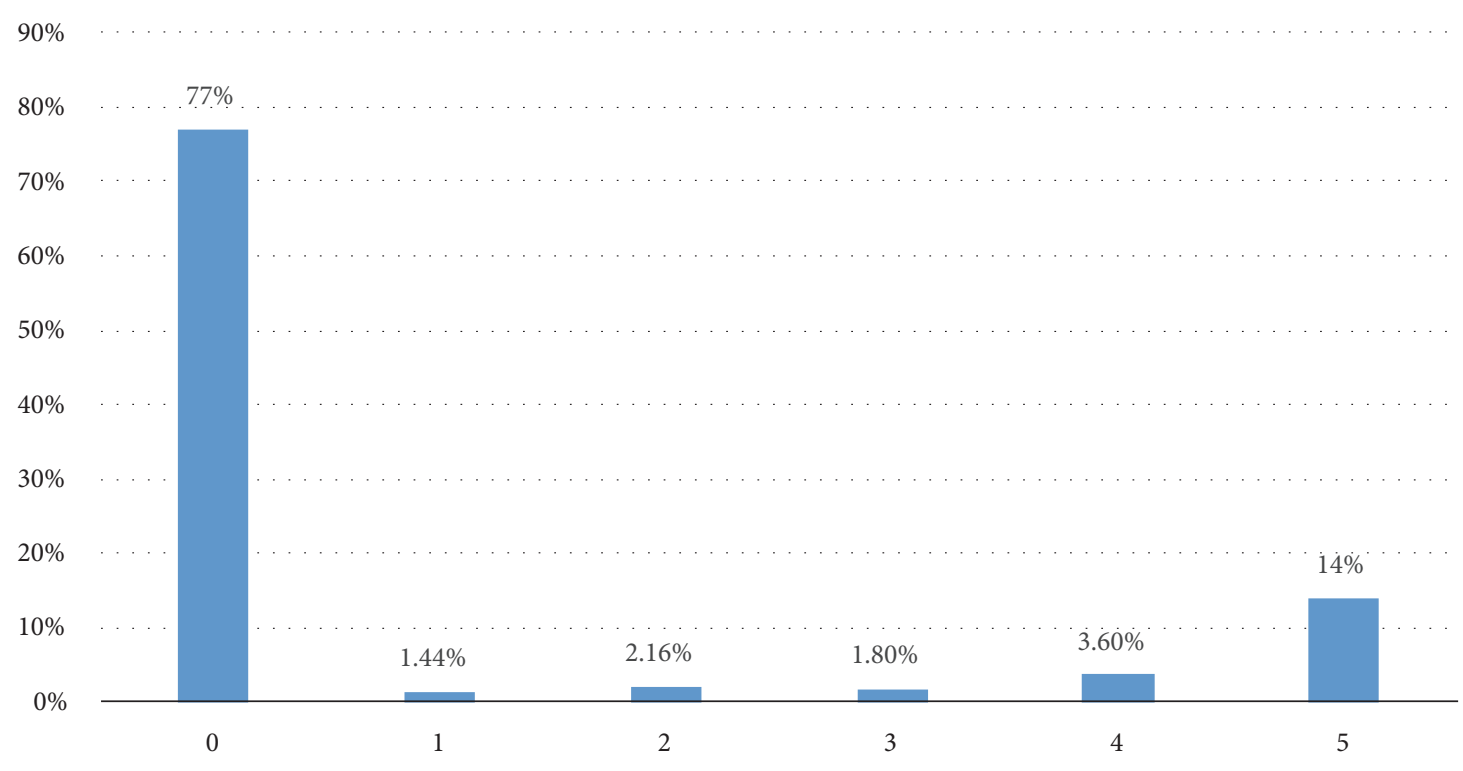

Number and percentage of identified stroke risk factors

FIGURE 1: Number and percentage of identified stroke risk factors.

TABLE 2: Socio-demographic characteristics associated with general knowledge of hypertensive patients.

\begin{tabular}{|c|c|c|c|c|c|}
\hline \multirow{2}{*}{ Variables } & \multicolumn{2}{|c|}{ Knowledge } & \multirow{2}{*}{ COR $(95 \% \mathrm{CI})$} & \multirow{2}{*}{$\operatorname{AOR}(95 \% \mathrm{CI})$} & \multirow{2}{*}{ P-value } \\
\hline & Good & poor & & & \\
\hline \multicolumn{6}{|l|}{ Age } \\
\hline$<45$ & 45 & 182 & $3.068(1.613-5.837)$ & $2.59(1.225-6.20)$ & $0.001 *$ \\
\hline$\geq 45$ & 22 & 29 & 1.00 & 1.00 & \\
\hline \multicolumn{6}{|l|}{ Sex } \\
\hline Female & 18 & 127 & 1.00 & & \\
\hline Male & 33 & 100 & $2.328(1.238-4.377)$ & & \\
\hline \multicolumn{6}{|l|}{ Marital status } \\
\hline Single & 7 & 9 & $3.033(3.30-27)$ & & \\
\hline Married & 41 & 59 & $10.05(1.33-7.53)$ & & \\
\hline Divorced & 2 & 22 & $3.93(0.33-4.5)$ & & \\
\hline Widowed & 1 & 39 & 1.00 & & \\
\hline \multicolumn{6}{|l|}{ Residence } \\
\hline Rural & 4 & 134 & 1 & & \\
\hline Urban & 44 & 95 & $12.41(4.745-32.470)$ & $3.549(1.191-10.573)$ & $0.023 *$ \\
\hline \multicolumn{6}{|l|}{ Level of education } \\
\hline Unable to read & 5 & 149 & 1.00 & 1.00 & \\
\hline Able to read and write & 46 & 78 & $17.57(6.711-46.024)$ & $7.12(2.298-22.10)$ & $0.001 *$ \\
\hline \multicolumn{6}{|l|}{ Income } \\
\hline Sufficient & 33 & 70 & $5.731(2.943-11.161)$ & $2.756(1.225-6.20)$ & $0.014 *$ \\
\hline Insufficient & 16 & 159 & 1.00 & 1.00 & \\
\hline
\end{tabular}

$N B$ : variables having a $(\mathrm{P} \leq 0.2)$ in bi variable (unadjusted) analysis included in the multivariable (adjusted) analysis. $*$ Statistically significant at $\mathrm{p}$-value $\leq 0.05$. $\mathrm{COR}=$ Crude Odd Ratio. $\mathrm{AOR}=$ Adjusted Odd Ratio.

risk factor profile of stroke patients [23, 24]. The possible difference in identification of hypertension as an important risk factor might be due to variability in health care systems regarding health education delivery; and it may be also due to the fact that majority of participants in the current study were uneducated with insufficient income who are less likely to get hypertension related information through internet, newspaper, and watching television.

The commonest stroke warning sign recognised by the patients was sudden weakness or paralysis on one side of the body (35.9\%), followed by unusual severe 
headache (16.2\%); and it is comparable to finding of Kuwaiti study, in which sudden weakness or paralysis on one side of the body was reported by $36.4 \%$ of participants [25].

The current study found a positive relationship between knowledge of stroke with hypertensive patients' age and educational level, in which those who were younger with high level of education participants had better knowledge regarding stroke risk factors and warning signs. These findings are consistent with previous studies $[17,18,26]$. This might be due to the fact that low level of education and old age may lead to limited interaction with society and therefore less interest in following medical developments, thereby resulting in a low level of health care knowledge and attitude about stroke. Moreover, financial status and education were also found to be the determinants of knowledge towards stroke [27]. Individuals residing in urban setting were more than three times more likely to have good knowledge about stroke; and it is in line with a study conducted in Ugandan population [16], which might be justified as urban residents are exposed to new information; most of them are social media followers, and because of the increasing prevalence of chronic disease they are interested to know the complication of hypertension, they have health facilities around them, and they have opportunity for education.

\section{Limitation}

Since the study was institutional based and excludes hospitalized patients, generalization of the findings to the general populace is limited; in addition, since it was confined to public hospital, hypertensive patients who are considered economically sufficient and educated may have follow-up at another private hospital and the study did not assess them. Moreover, the study is limited by the fact that it was crosssectional and used close-ended questions. This might have limited the participants' responses regarding their knowledge and attitudes towards stroke. However, the answer choices for each question were worded to cover a wide range of response possibilities.

\section{Conclusion}

The present study showed that knowledge regarding stroke risk factors and warning signs was significantly low among hypertensive patients, in which majority of participants were unable to identify any risk factors and warning signs of stroke. Being young, urban residence, being educated, and having sufficient income were significant predictors of good knowledge towards stroke risk factors and warning signs. These findings suggest the need for all stakeholders to emphasize stroke education to help individuals to understand and manage stroke risk factors as well as its warning signs through public or social media and school and health education crucially for low-income high risk subjects.

\author{
Abbreviations \\ AOR: $\quad$ Adjusted Odds Ratio \\ CI: Confidence Interval \\ COR: Crude Odds Ratio \\ Epi info: Statistical Package for Epidemiological \\ Information Analysis \\ SPSS: Statistical Package for Social Sciences.
}

\section{Data Availability}

The datasets used and analysed during the study are available from the corresponding author on reasonable request.

\section{Ethical Approval}

This study was approved by the ethical committee of University of Gondar.

\section{Consent}

Verbal informed consent from the patients was also obtained before conducting the study. Participants' information obtained was kept confidential.

\section{Disclosure}

No financial support was gained to conduct the study.

\section{Conflicts of Interest}

The authors declare that there are no conflicts of interest.

\section{Authors' Contributions}

Addisu Taye was responsible for the initiation, design, and implementation of the study, carrying out the statistical analysis, writing up, and preparing the paper. Netsanet Habte and Tesfamichael G. Mariam participated in writing, reviewing, and approval of the proposal and prepared the paper for publication. All the authors read and approved the final paper.

\section{Acknowledgments}

The authors thank all the staff members of Felege Hiwot Referral Hospital for their contribution during data collection and University of Gondar for giving ethical clearance. The authors would like to thank also the study participants for giving their consent to participate in the study.

\section{References}

[1] V. L. Feigin, M. H. Forouzanfar, R. Krishnamurthi et al., "Global and regional burden of stroke during 1990-2010: findings from the Global Burden of Disease Study 2010," The Lancet, vol. 383, no. 9913, pp. 245-255, 2014.

[2] K. Strong, C. Mathers, and R. Bonita, "Preventing stroke: saving lives around the world," The Lancet Neurology, vol. 6, no. 2, pp. 182-187, 2007. 
[3] V. L. Feigin, C. M. Lawes, D. A. Bennett, S. L. Barker-Collo, and V. Parag, "Worldwide stroke incidence and early case fatality reported in 56 population-based studies: a systematic review," The Lancet Neurology, vol. 8, no. 4, pp. 355-369, 2009.

[4] M. Abebe and R. T. Haimanot, "Cerebrovascular accidents in Ethiopia.," Ethiopian Medical Journal, vol. 28, no. 2, pp. 53-61, 1990.

[5] "World life expectancy," 2018, http://www.worldlifeexpectancy .com/ethiopia-stroke.

[6] E. Sagui, P. S. M'Baye, C. Dubecq et al., "Ischemic and hemorrhagic strokes in Dakar, Senegal: a hospital-based study," Stroke, vol. 36, no. 9, pp. 1844-1847, 2005.

[7] G. Zenebe, M. Alemayehu, and J. Asmera, "Characteristics and outcomes of stroke at Tikur Anbessa Teaching Hospital, Ethiopia," Ethiopian Medical Journal, vol. 43, no. 4, pp. 251-259, 2005.

[8] B. Deresse and D. Shaweno, "Epidemiology and in-hospital outcome of stroke in South Ethiopia," Journal of the Neurological Sciences, vol. 355, no. 1-2, pp. 138-142, 2015.

[9] World Health Organizatio, Noncommunicable Diseases Country Profiles, World Health Organization, Geneva, Switzerland, 2013.

[10] P. A. Wolf, R. B. D’Agostino, M. A. O’Neal et al., "Secular trends in stroke incidence and mortality: the framingham study," Stroke, vol. 23, no. 11, pp. 1551-1555, 1992.

[11] S. Seshadri, A. Beiser, M. Kelly-Hayes et al., "The lifetime risk of stroke: estimates from the framingham study," Stroke, vol. 37, no. 2, pp. 345-350, 2006.

[12] E. S. Greffie, T. Mitiku, and S. Getahun, "Clinical pattern and outcome of stroke in a referral hospital, Northwest Ethiopia," Clinical Medicine Research, vol. 4, no. 6, pp. 182-188, 2015.

[13] D. W. Droste, J. Safo, R. J. Metz, and N. Osada, "Stroke awareness in Luxemburg: Deficit concerning symptoms and risk factors," Clinical Medicine Insights: Cardiology, vol. 8, Supplement 2, pp. 9-13, 2014.

[14] R. O. Akinyemi, O. S. Ogah, R. F. Ogundipe et al., "Knowledge and perception of stroke amongst hospital workers in an African community," European Journal of Neurology, vol. 16, no. 9, pp. 998-1003, 2009.

[15] O. Ayanniyi, O. Akande, and A. F. Mustapha, "Knowledge and perception of stroke among adults in Osogbo, Nigeria," African Journal of Medicine and Medical Sciences, vol. 35, no. 4, pp. 447452, 2006.

[16] S. S. Yoon, R. F. Heller, C. Levi, J. Wiggers, and P. E. Fitzgerald, "Knowledge of stroke risk factors, warning symptoms, and treatment among an Australian urban population," Stroke, vol. 32, no. 8, pp. 1926-1930, 2001.

[17] S. Raj, American Samoa NCD Risk Factors STEPS Report, Suva, Fiji, 2007.

[18] J. Nakibuuka, M. Sajatovic, E. Katabira, E. Ddumba, J. ByakikaTusiime, and A. J. Furlan, "Knowledge and perception of stroke: a population-based survey in Uganda," ISRN Stroke, vol. 2014, Article ID 309106, 7 pages, 2014.

[19] J. Yang, M. Zheng, S. Chen et al., "A survey of the perceived risk for stroke among community residents in western urban China," PloS One, vol. 8, Article ID e73578, 2013.

[20] F. Nausheen and D. Haider, "Awareness about the signs, symptoms and the risk factors of stroke in patients with stroke: a multicentre study," Pakistan Journal of Neurological Sciences (PJNS), vol. 11, no. 3, pp. 9-13, 2016.

[21] A. Hickey, D. Holly, H. McGee, R. Conroy, and E. Shelley, "Knowledge of stroke risk factors and warning signs in Ireland: development and application of the Stroke Awareness Questionnaire (SAQ)," International Journal of Stroke, vol. 7, no. 4, pp. 298-306, 2012.

[22] M. A. Kuadran, F. A. Fahad, Y. A. Osama, E. F. Mohammed, and H. A. Ali, "Knowledge and attitude of stroke among Saudi population in Riyadh, Kingdom of Saudi Arabia," International Journal of Academic Scientific Research, vol. 5, no. 1, pp. 149-157, 2017.

[23] M. Wijdan, A. Ghufran, A. Haneen, and M. Mohammed, "Public knowledge of stroke amongst a saudi population," World Journal of Research and Review, vol. 3, no. 2, pp. 10-12, 2016.

[24] S. S. Mazloomy, M. H. Baghianimoghadam, M. H. Ehrampoush, B. Baghianimoghadam, M. Mazidi, and M. R. Mozayan, "A study of the knowledge, attitudes, and practices (KAP) of the women referred to health centers for cardiovascular disease (CVDs) and their risk factors," Health Care for Women International, vol. 35, no. 1, pp. 50-59, 2014.

[25] W. M. Feinberg, "Primary and secondary stroke prevention," Current Opinion in Neurology, vol. 9, no. 1, pp. 46-52, 1996.

[26] K. Lundelin, A. Graciani, J. Garcia-Puig et al., "Knowledge of stroke warning symptoms and intended action in response to stroke in Spain: a nationwide population-based study," Cerebrovascular Diseases, vol. 34, no. 2, 2012.

[27] M. A. Komolafe, M. O. B. Olaogu, A. M. Adebiyi, A. O. Obembe, M. B. Fawale, and A. A. Adebowale, "Stroke risk factors among participants of a world stroke day awareness program in SouthWestern Nigeria," Nigerian Journal of Clinical Practice, vol. 18, no. 6, pp. 807-809, 2015. 


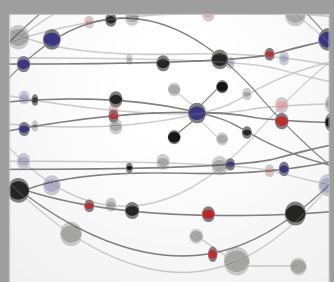

The Scientific World Journal
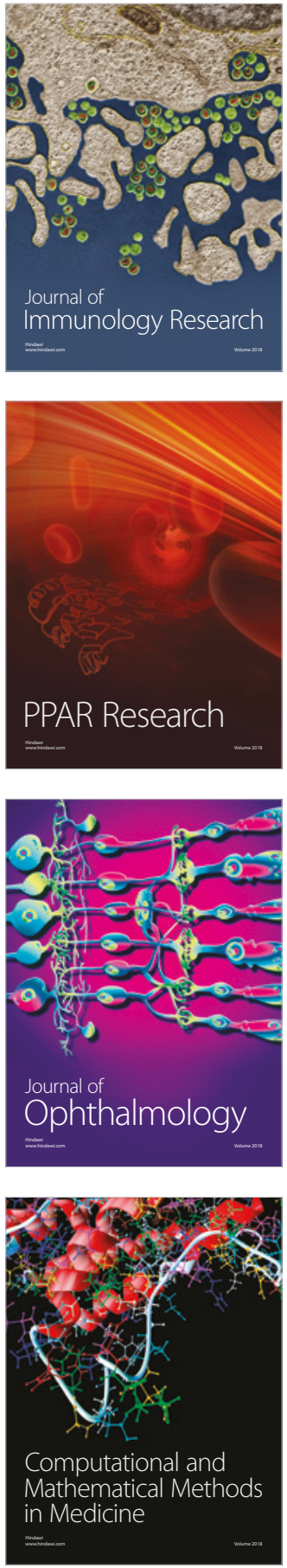

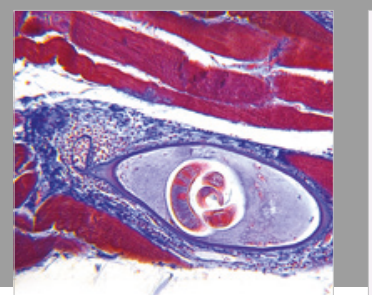

Gastroenterology Research and Practice

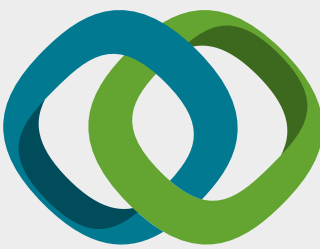

\section{Hindawi}

Submit your manuscripts at

www.hindawi.com
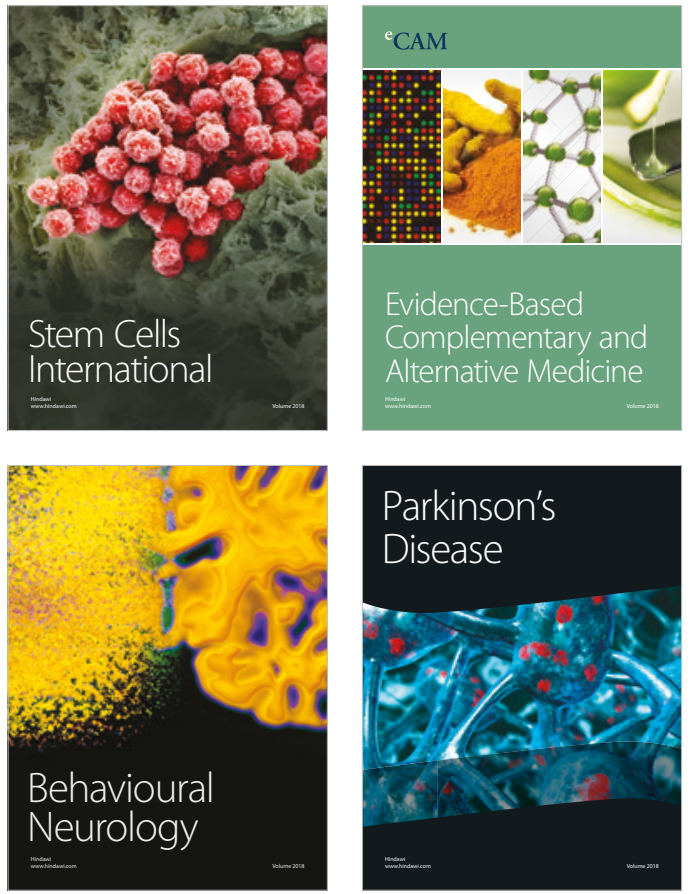

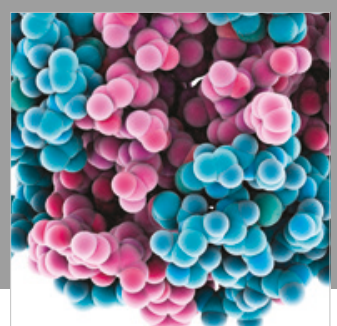

ournal of

Diabetes Research

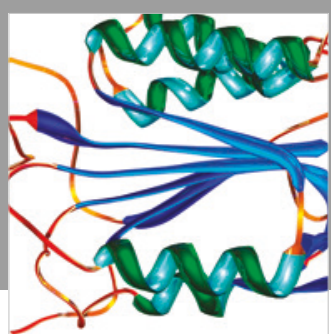

Disease Markers
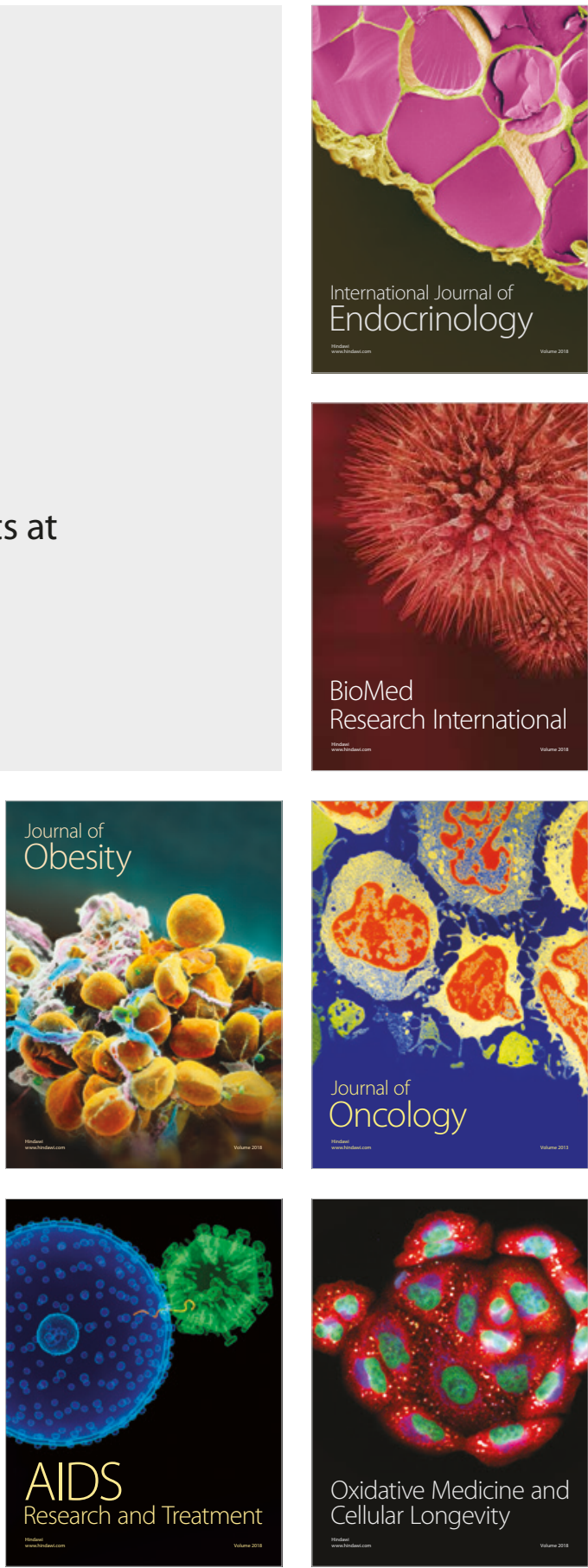